\title{
Daylighting, Daylight Simulation and Public Health: Low-Energy Lighting for Optimal Vision/Visual Acuity and Health/Wellbeing
}

\author{
E. V. Ellis ${ }^{1 *}$, N. B. Handly ${ }^{1}$, D. L. McEachron ${ }^{1}$, \\ A. Del Risco ${ }^{2}$, M. Baynard ${ }^{1}$ \\ ${ }^{1}$ Drexel University, Philadelphia, USA \\ ${ }^{2}$ Florida State University, Tallahassee, USA \\ *Corresponding author. Tel: +01 2153804276, Fax: +01 2157822226, E-mail: genaellis@drexel.edu
}

\begin{abstract}
Indoor Ecology (IE) is an emerging research field that aims to develop new approaches and technologies which allow indoor environments and occupants to dynamically co-adapt to each other in order to enhance human wellbeing and productivity while simultaneously optimizing energy efficiency. The central idea in IE is that humans, building systems and the interior environment form a single, integrated complex 'ecosystem'. One way to IE optimization is though lighting, especially daylighting and daylight simulation. Current approaches to energy-efficient buildings emphasize only limited aspects of interior lighting, such as the carbon footprint, without regard to the multiple effects lighting has on human health, wellbeing and productivity which must be considered if truly sustainable interior spaces are to be designed. This paper documents five ongoing investigations which study various aspects of the lighting-human interaction in a variety of circumstances. For example, students in the classroom setting are exposed to wide changes in lighting as well as inadequate light during early classes, likely affecting attention, retention and performance. Subjects displayed a marked preference for natural lighting when given the option; supporting a general hypothesis that daylighting might be a solution to the twin problems of promoting health and productivity while decreasing energy use.
\end{abstract}

Keywords: Daylighting, Low-energy lighting, Visual acuity, Health, Wellbeing

\section{Introduction}

The emerging discipline of Indoor Ecology seeks to develop the theories, methodologies and technologies needed to recast building design and architectural space in terms of flexible, sustainable and evolving human-building ecosystems. As part of this larger initiative, the effects of environmental lighting on human physiology and behavior must be investigated alongside the physical parameters of architectural space. The objective of the current research initiative into the effects of lighting on vision/visual acuity and health/wellbeing is to establish guidelines that can assist in the development of sustainable lighting solutions to promote the health and wellbeing of building occupants. This process-based research investigation looks to nature as a way of remodeling the built environment by considering the human-building relationship as a complex, evolving ecological network. Such an approach requires that environmental lighting be viewed from multiple perspectives - visual acuity, mood, chronobiology, health, energy efficiency, etc. - in order to inform the technological development of sustainable interior lighting systems [1]. Sustainable in this sense is broader that typically used in architectural design and includes the effects of light on human health and productivity as well as energy-efficient lighting design. The overall on-going research objective is to develop design criteria, guidelines and parameters to support the development of low-energy sustainable architecture at the nexus of health, energy and technology.

\subsection{Background}

Recent research indicates that lighting has increasingly become a public health issue [2]. These studies have shown that individuals working in natural sunlight are more productive, more effective, and happier than those who work under traditional artificial light. In addition, several studies have demonstrated a connection between environmental lighting levels and higher productivity and better performance from building occupants [6, 7]. Natural changes in 
daylight balance the body's circadian rhythm, which determines sleeping and eating patterns, cognitive activity, heart rate, hormone levels - in fact, virtually all physiological and behavioral parameters. Circadian phase shift and transmeridian travel have been shown to contribute to jetlag, seasonal affective disorder (SAD), delayed sleep phase syndrome (DSPS), and is implicated in more various diseases and disorders, including cancer [3]. In industrialized nations it is estimated that up to $20 \%$ of the workforce are involved in some kind of shift work [4] which is associated with exposure to unusual or abnormal levels and/or patterns of light and dark. Studies have associated these unusual levels and patterns with higher incidences of breast cancer and colorectal cancers [1]. Thus, the sustainability of human productivity and well-being, even life itself, is directly tied to environmental lighting.

Lighting is also a sustainability issue in terms of energy use. Buildings consume $39 \%$ of the primary energy in the United States - on average 18\% is used by lighting systems alone [5]. Also, the heat produced by a lighting system can generate up to $24 \%$ of the total building cooling load [6]. Proper lighting utilization using low-energy systems that generate little heat could result in significant cooling energy savings for buildings and a smaller carbon footprint.

The twin requirements of promoting human health and productivity and designing energy efficient lighting systems appear to be at odds. How can lighting be designed sufficiently bright enough to sustain human health and productivity while suitably energy efficient enough to sustain the planet? One possibility is the creative use of natural daylight. Daylight brings enough light to meet lighting needs of 50 to $70 \%$ of the occupancy period in the temperate zone of the earth while saving energy up to $50 \%$ of the gross full yearly use of light $[8,9]$.

For proper health and energy savings it is important to understand how light affects physiology and behavior. Ocular light, or light reaching the eye, serves two major functions: vision and control of circadian rhythm [10]. Daylighting provides the quality light necessary for maximum vision and visual acuity [11] and provides the full spectrum of light needed for health and wellbeing [3]. Circadian rhythm is regulated by changes in visible light from the sun throughout the day [12] and is controlled daily by the full spectrum of natural light together with darkness in the environment [10].

\subsection{Physiology and Daylight}

Natural daylight is crucial to promote productivity, health and wellbeing due to light's visual and non-visual effects. In addition to object recognition or visual information, light provides data on the timing and intensity of light and dark to synchronize the body's biological rhythms. Photonic information (non-visual effects of light) is transmitted from the eye to the suprachiasmatic nucleus (SCN) located in the hypothalamic region in the center of the brain, leading to a cascade of hormonal changes in the pituitary, pineal, adrenal and thyroid glands.

The SCN serves as master pacemaker or biological clock in humans, synchronizing the circadian rhythms that regulate and modify virtually every physiological and behavioral process in the human body. The human SCN displays a natural period slightly longer than 24 hours and must be reset by light of the appropriate spectrum and intensity, at the proper time, to provide a consistent temporal order. When this temporal order is significantly disrupted through inappropriate interior lighting, for example - it can lead to damaging emotional and physiological effects such as those associated with seasonal affective disorder, jet lag, delayed sleep phase syndrome, and may exacerbate serious conditions such as cancer. These effects are especially evidenced by people involved in shift work $[13,14,15]$, such as the doctors and staff working in the Emergency Department at Hahnemann who are part of this research. 
The hominid ancestors of humans did not live in buildings and evolved their circadian system - which present humans have inherited - exposed to the natural day/night cycle. The full spectrum of light available in this cycle includes UVA, UVB and visible light: at noon there is high intensity in the blue light region, in the late afternoon blue light is preferentially scattered out of (removed from) incoming sunlight so that the late afternoon sun provides red and orange light, and when the sun sets it becomes dark. Circadian rhythms are controlled primarily by daily exposure to levels of light in the blue-green spectrum together with alternating darkness in the environment. Blue light triggers the production of serotonin in the body, which enhances alertness and cognitive performance, while red or amber light signals the onset of dusk; the absence of light encourages melatonin secretion [16, 17]. Returning buildings to a natural light environment through the use of daylighting or mimicking the full spectrum of natural light using energy-efficient artificial lighting would both conserve energy and promote the wellbeing of building occupants [18].

\section{Methodology}

There are five on-going investigations to determine the effects of a variety of lighting options in different architectural settings. These studies are designed to test environmental preference for natural light, artificial light effects on human health and productivity, different artificial light sources effects on vision and visual acuity with respect to energy use, and the effects of light shelves on indoor illumination levels. Preliminary results are documented in this paper.

\section{Results}

\subsection{Hahnemann Hospital Emergency Department Waiting Room Daylighting Study}

The waiting room of the Hahnemann Hospital Emergency Department is a poorly monitored space: patients suffering from an accident, illness or even fear, are also unsure as to how long they may be waiting or what will happen once they see the doctor. After the recent death of a Philadelphia man waiting for care, attention has been refocused to emergency department waiting rooms. While it is not clear what led to his death, the event does suggest that health care providers should know more about what is happening to patients, both in the short and long term, while they are in the waiting room of emergency departments.

Although the effects of the environmental lighting should influence designs for healthcare spaces, this is rarely the case. Light exposure of specific frequencies and intensities has been shown to affect mood and performance [20, 21, 22] and even treat certain aspects of depression [23]. Not known is whether lighting can affect a person's health and wellbeing over short and irregular time periods such as while waiting for care at emergency departments. Waiting durations vary from less than a minute to as much as 12 hours - longer wait times are associated with increasing levels of impatience and agitation.

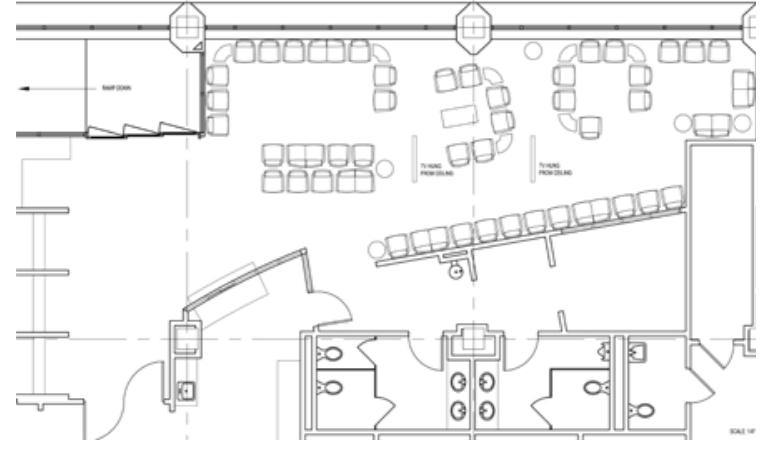

Fig. 1. Plan of the Hahnemann Emergency Department Waiting Room (north side top of drawing).

In addition to effects of lighting on patient attitude and mood, lighting may also affect the underlying health problem that brought the patient to the hospital in the first place. The current lighting of the Emergency Department waiting room at Hahnemann Medical Center was analyzed as a first step in assessing effects of lighting on waiting patients (Fig. 1). 
The next step is to determine the effects of the current lighting on patients. The initial hypothesis is that patients will aggregate in areas of high light intensity or natural lighting. In the daytime, the seats adjacent to the north windows receive the most natural daylight. The prediction is there will be a natural gradient of persons within the waiting room tending to sit near the windows. However, at night there is little difference in lighting (all artificial lighting) and no gradient of persons is expected as a result of lighting conditions. The artificially-lit waiting room of the evening hours will be used as a control to determine if there is a preference to sit near the windows. Other factors must be considered such as location relative to televisions, where other persons have already occupied a seat or even proximity to bathrooms or vending machines. The lighting measurements will be correlated to seat positions in another series of measurements. Data is presently being gathered; initial results support the hypothesis suggesting a trend to prefer sitting near the windows in daylight hours.

\subsection{Hahnemann Emergency Department Baseline Staff Productivity Study}

Another aspect of patient care is the performance of the health care providers. Given the well known performance deficits associated with circadian disruption and sleep deprivation, is it possible for environmental lighting to act as a counter agent to these effects? Current practice for emergency room service delivery involves doctors participating in schedules that involve 8- or 10-hour shifts of two days of daytime, two days of afternoon/evening, two days of overnight and two days off. An initial staff productivity study will serve as a baseline inventory of sleep, self reported quality of wellbeing, burnout, sleepiness and preferred phase of circadian activity as well as the Emergency Department (ED) lighting environment. In this second ED study, resident physicians will wear light sensing wrist actigraphs that measure movement to assess objective sleep-wake activity patterns in different lighting conditions for one work cycle. Within the ED, lighting apparently varies little and there is no natural lighting once inside the patient treatment areas. However, lighting conditions may change based upon specific tasks being undertaken and/or the influence of lighting on performance may be task dependent. Lighting levels will be measured and correlated to tasks to assess how the Emergency Department lighting could be better designed to support ED staff performance.

\subsection{Lighting and the Educational Environment}

It is well known that time of day affects performance and learning. Sleep deprivation and fatigue are detrimental to an array of neurocognitive functions and, by extension, decrease learning. However, these observations have not been systematically applied to scheduling classes with the goal of enhancing a student's learning experience.

Lighting levels are being documented in several Drexel University classrooms and show significant variation from room to room and at different times of day in the same room. In fact, the lighting levels have been found to vary significantly from desk to desk within a single room even when the room is artificially illuminated. The discrepancy in lighting levels is even more pronounced when the room also has access to natural daylight, compounded with orientation to the sun (whether east, west, north or south orientation). To determine how these varying lighting conditions effect learning, students are being monitored for activity and light exposure using wrist actigraphy (Fig. 2). The data will be

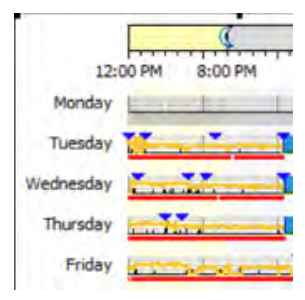

Fig. 2. Actogram from wrist actigraph demonstrating ambient light exposure, sleep, rest, and activity periods for an average subject over 21 days. 
cross-referenced with the student's performance to determine the effects of lighting and sleep/wake cycles on academic achievement. Further studies will evaluate classroom seating position with respect to lighting and effects of lighting on mood, sleepiness and performance.

Preliminary investigations consist of data collection using wrist actigraphy for 2 weeks during a school term. Weekdays were analyzed to determine the average light exposure students received during the day. Light was recorded in 60 second epochs. 180 epochs were averaged to create six, 3 hour bins from 06:00-24:00. Average light exposure (lux) was compared across the bins. While previous analysis failed to reveal a significant exposure to ambient light during the night (24:00-06:00), daytime exposure was shown to vary significantly by time of day. A one-way ANOVA was used to test for differences in average light exposure in 3 hour bins from 06:00-24:00. Exposure differed significantly across the six time bins, F (5, $102)=3.78, p=.003$. Also, a trend toward increasing light exposure was seen as a result of time of day with the hours of 12:00-14:00 showing the highest average lux per subject. Additionally, during students' earliest waking hours, from 06:00-09:00, analysis revealed significantly reduced light levels, equivalent to the sleeping environment, despite student's schedules and activity measurements correlating this time period as active class time.

\section{4. $\quad$ Light Source, Vision and Visual Acuity}

Not only are lighting levels, light with respect to time of day, and physiologically experiencing the full spectrum of natural daylight important for the work environment, but also the quality of the light can be crucial-especially in an emergency medicine situation when the attending physician may be tired and yet responsible for completing tasks that require precise visual acuity, such as making incisions and stitching wounds.

During the summer 2010, five lighting experiments were set up to compare and contrast five different light sources for visual acuity and comfort, which were crossreferenced with age, gender and whether or not corrective lenses were used. Each lighting experiment had an eye chart with verse from Ralph Waldo Emerson's The Conduct of Life, with point sizes varying from $1 \mathrm{pt}$ to $7 \mathrm{pt}$, each illuminated by a different light source. The test subject looked through goggles to ensure the same focal distance from the eye chart and selected the smallest point size that could be read. The lighting level was been set at +/- 530-650 lux for each of the four artificial light sources: LED, Phillips incandescent, compact fluorescent and GE incandescent (Fig. 3). The fifth lighting experiment used available natural daylight and the test subject noted the lighting level at the time of the test; daylighting levels tended to vary within the range set up for the artificial lighting sources at $+/-530-650$ lux. The test subject was requested to indicate which one of the light sources was the most comfortable (Fig. 4). Sixtyfive people were surveyed with ages ranging from 9 to 77 years. While the use of corrective lenses did not seem to affect the study, the daylight source was overwhelmingly preferred. However, this was not the case during the spring when daylighting levels varied 200-500 lux.

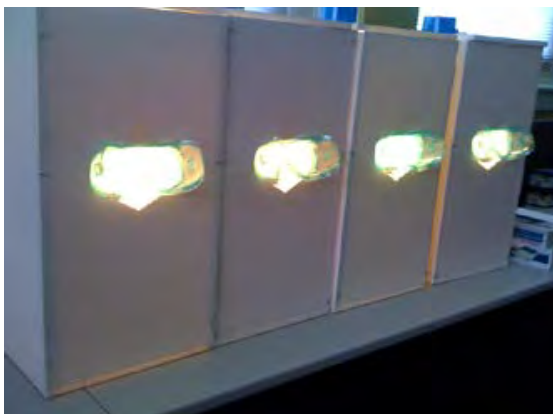

Fig. 3. Light Boxes, from left to right: LED, Phillips incandescent, CFL, GE incandescent

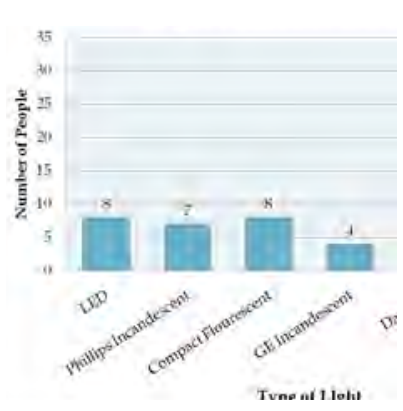

Fig. 4. Light Source Preference 
Determining quality of light with respect to light source and energy consumption is critical to meet today's energy conservation needs. Daylighting is ideal because it consumes no energy and is cost-free. On the other hand, radiant energy from light results in heat gain; potentially in the winter a reduction in heating costs, while in the summer an increase in cooling loads. Indirect daylight is ideal because of lowered radiant heat gains. A comparison of the artificial light sources used in this experiment reveals that although users indicated little preference between the artificial light sources, while the LED (light emitting diode) light source is considerably more sustainable, it costs nearly double the CFL (compact Fluorescent); however, both use considerably less energy than either incandescent (Table 1). Additionally, while not measured in this study, both the LED and CFL also generate less heat.

Table 1. Artificial light sources.

\begin{tabular}{|c|c|c|c|}
\hline $\begin{array}{l}\text { LED: Pharox } 40 \\
\text { Warm White Light }\end{array}$ & $\begin{array}{l}\text { Incandescent: Philips } \\
\text { Duramax R20 }\end{array}$ & $\begin{array}{c}\text { Compact } \\
\text { Fluorescent: } \\
\text { Ecosmart Soft White } \\
\text { Cold Cathode }\end{array}$ & $\begin{array}{l}\text { Incandescent: GE } \\
\text { Soft White } 25\end{array}$ \\
\hline $\begin{array}{ccc}\begin{array}{c}230 \\
\text { lumens }\end{array} & 5 \mathrm{~W} & \begin{array}{c}36 \mathrm{~K} \\
\text { hours }\end{array} \\
\end{array}$ & $\begin{array}{cc}205 & 30 \mathrm{~W} \\
\text { lumens } & \\
\end{array}$ & $\begin{array}{ccc}\begin{array}{c}200 \\
\text { lumens }\end{array} & 5 \mathrm{~W} & \begin{array}{c}20 \mathrm{~K} \\
\text { hours }\end{array} \\
\end{array}$ & $\begin{array}{ll}25 \mathrm{~W} & 2.5 \mathrm{~K} \\
& \text { hours } \\
\end{array}$ \\
\hline $\begin{array}{l}\text { No mercury, no UV, } \\
100 \% \text { recyclable }\end{array}$ & & contains mercury & \\
\hline $\begin{array}{c}\text { cost over 36,500 } \\
\text { hours }=\$ 76.38\end{array}$ & $\begin{array}{l}\text { Cost over 36,500 } \\
\text { hours }=\$ 219.15\end{array}$ & $\begin{array}{c}\text { Cost over } 36,500 \\
\text { hours }=\$ 39.35\end{array}$ & $\begin{array}{l}\text { Cost over } 36,500 \\
\text { hours }=\$ 159.15\end{array}$ \\
\hline
\end{tabular}

\subsection{Natural Daylighting and Light Shelf Efficacy}

Lighting energy accounts for a large portion (30-50\%) of total energy consumption of typical commercial buildings [19], and about $15 \%$ percent of residential consumption in the U.S. [5]. Daylight generates enough light to meet lighting requirements of 50 to $70 \%$ of the occupancy period in the temperate zone of the earth. Energy savings by using daylighting can be up to $50 \%$ of the gross full yearly use of light for interior conditions [8, 9]. For these reasons, techniques that can maximize daylight use in indoor spaces while minimizing heat gain would be useful to ensure both quality light and energy savings in buildings.

A south-facing room was used as a test site. It is a typical office plan illuminated by windows all along the south wall from about 42" above the floor to the ceiling at ten feet above the floor. The orientation is skewed from true south as indicated in the plan (Fig. 5). Light shelves were installed along the central horizontal dividing mullion at approximately six feet above the floor level. A 99.7\% reflective coating provided by $3 \mathrm{M}$ Corporation was installed on the top surface of the light shelf and on the ceiling above to redirect the reflected sunlight back down into the room. Lighting levels were documented at one hour intervals from 10:00-15:00. It was noted whether or not it was Sunny (Clear Sky), Partly Cloudy, Cloudy, or Rainy. Three separate readings were taken each hour: no light shelf, light shelf horizontal to the floor, and light shelf inclined at $10^{\circ}$ below the horizontal. Readings were taken on twenty separate days over a period of six weeks at three locations as indicated on the plan (Fig. 6).

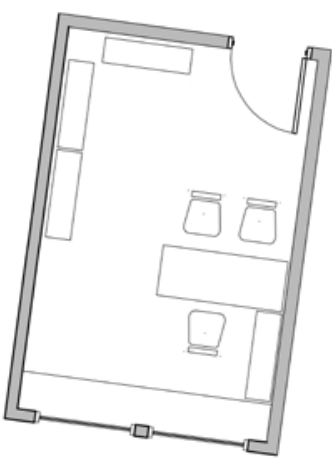

Fig. 5. Office

(oriented north up).

Preliminary results suggest that light shelves help to evenly distribute interior lighting levels across the room when located on south-facing windows; glare is reduced at the window due to 
the shelf shading adjacent work surfaces while lighting levels are increased at work surfaces within five to eight feet from the window (Fig. 7). Surfaces beyond eight feet receive much less benefit. Daylighting is most effective when the sun is perpendicular to the window, explaining why illumination levels for this test location were highest at 14:00 instead of noon.

\section{Conclusions}

While human behavior is occasionally considered in the design of low-energy architecture, energy use and efficiency can often take precedence over human comfort, performance and/or wellbeing. Buildings have been designed to efficiently use energy while illuminating building interiors. However, rarely is visual acuity a consideration in lighting design nor are the effects of lighting on physiology and behavior. As a result, lighting is often energy-efficient while building occupants have difficulty succeeding in tasks requiring keen vision, such as suturing a wound or reading fine-print text. Additionally, buildings with 24 hour illumination generally produce the same intensity and wavelengths throughout the period, increasing chances for circadian disruptions with consequent health and performance decrements. The quality and timing of light should be controlled to ensure the physical and mental wellbeing of building occupants. Future areas for research include: 1) evaluating the feasibility of artificially mimicking the full spectrum of light by phase-shifting the day of night-shift workers to reset their biological clocks to be in sync with their natural circadian rhythms; 2) optimizing the educational environment by coordinating course schedules with time of day and classroom lighting levels to enhance student academic performance and alertness; and 3) developing criteria for sustainable architectural design at the nexus of health, energy and technology.

\section{References}

[1] J. Benyus, Biomimicry: Innovation Inspired by Nature, New York: Harper Collins, 1997.

[2] S.M. Pauley, Lighting for the human circadian clock: recent research indicates that lighting has become a public health issue, Medical Hypotheses 63, 2004, pp. 588-596.

[3] J.E. Roberts, Therapeutic Effects of Light in Humans, Photobiology for the $21^{\text {st }}$ Century, edited by Thomas P. Coohill and Dennis P. Valenzeno, Overland Park, Kansas: Valdenmar Publishing Company, 2001, Chapter 2, pp. 17-29.

[4] A.R. Webb, Considerations for lighting in the built environment: Non-visual effects of light, Energy and Buildings 38, 2006, pp. 721-727.

[5] DOE, 2006 Buildings Energy Data Book, U.S. Department of Energy, http://buildingsdatabook.eren.doe.gov/.

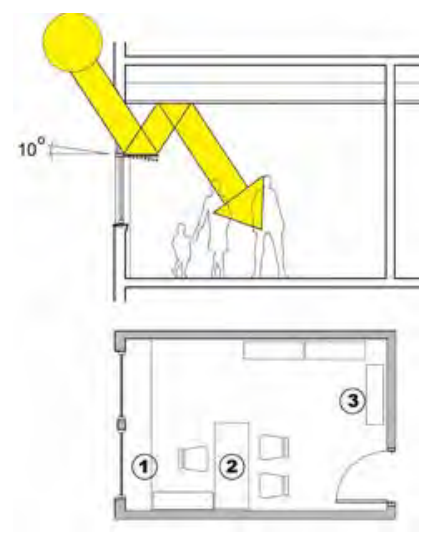

Fig. 6. Section through office showing light shelf and locations of daylight readings.
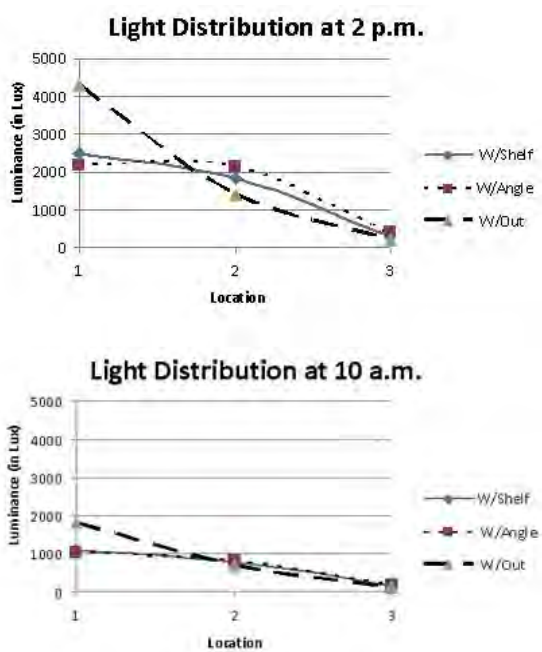

Fig. 7. Light distribution. 
[6] R. P. Leslie, Review: Capturing the Daylight Dividend in Buildings, Why and How?, Building and Environment 38, 2003, pp. 381-385.

[7] C. Fay, Daylighting and Productivity A Literature Review, Lighting Research Center, Rensselaer Polytechnic Institute, 2002, Report of Project "Cross-Cutting R\&D on Adaptive Full-Spectrum Solar Energy Systems for More Efficient and Affordable Use of Solar Energy in Buildings and Hybrid Photo-Bioreactors” sponsored by U.S. Department of Energy.

[8] M. Fontoynont, Perceived Performance of Daylighting Systems: Lighting Efficacy and Agreeableness, Solar Energy 73:2, 2002, pp. 83-94.

[9] E. Ne'eman and D. Shrifteilig, Daylighting Buildings in a Hot Climate, Energy and Buildings 4, 1982, pp. 195-204.

[10]J.E. Roberts, Daylight as a Visual Stimulus, Light Congress 2008, presentation.

[11]A.F. Bliss, The Chemistry of Daylight Vision, Journal of General Physiology 1946, pp. 277-297.

[12] J. Aschoff, Response curves in circadian periodicity, Circadian Clocks (Edited by J. Aschoff), North-Holland, Amsterdam, 1965, pp 95-111.

[13]A. Aanonsen, Medical problems of shift work, Indust. Med. Surg. 28, 1959, pp. 422-427.

[14]T. Akestedt and M. Gillber, Sleep disturbances and shift work, Advances Biosciences 30, 1981, pp. 127-137.

[15]C. Czeisler, M. Johnson, J. Duffy, E. Brown, J. Ronda, and R. Kronauer, Exposure to bright light and darkness to treat physiologic maladaptation to night work, New England Journal of Medicine 322, 1990, pp. 1253-1259.

[16]S. Kaplan, The Restorative Benefits of Nature: Toward an Integrative Approach, Journal of Environmental Psychology 15, 1995, pp. 169-182.

[17] V.Lubkin, P. Beizai and A. Sadun, The Eye as Metronome of the Body, Survey of Ophthalmology 47:1, 2002, pp. 17-26.

[18]P.R. Mills, S.C. Tomkins and L.J.M. Schlangen, The effect of high correlated colour temperature office lighting on employee wellbeing and work performance, Journal of Circadian Rhythms 5, 2007, p. 2.

[19]R. Bevington and A. H. Rosenfeld, Energy for Buildings and Homes, Energy for Planet Earth, Scientifc American, 1991.

[20]Daurat, A., Aquirre, A., Foret, J., Gonnet, P., Keromes, A., and Benoit, O. (1993). Bright light affects alertness and performance during a 24-h constant routine. Physiol. Behav. 53: 929-936.

[21]Dawson, D. and Campbell, S.C. (1991). Timed exposure to bright light improves sleep and alertness during simulated night shifts. Sleep 14: 511-516.

[22]Brainard, G.C., Sherry, D., Skewerer, R.G., Waxler, M., Kelly, K., Rosenthal, N.E. (1990). Effects of different wavelengths in seasonal affective disorder. J. Affective Disorders 20: 209-216.

[23]Kent, S., McClure, L., Crosson, W., Arnett, D., Wadley, V. and Sathiakumar, N. (2009). Effect of sunlight exposure on cognitive function among depressed and non-depressed participants: a REGARDS cross-sectional study. Environmental Health 8: 34 doi:10.1186/1476-069X-8-34. 